\title{
Phase II (NAVIGATE-AD study) Results of LY3202626 Effects on Patients with Mild Alzheimer's Disease Dementia
}

\author{
Albert C. Lo ${ }^{\mathrm{a}, *}$, Cynthia Duggan Evans ${ }^{\mathrm{a}}$, Michele Mancini ${ }^{\mathrm{a}}$, Hong Wang ${ }^{\mathrm{a}}$, Sergey Shcherbinin ${ }^{\mathrm{a}}$, \\ Ming Lu ${ }^{\mathrm{b}}$, Fanni Natanegara ${ }^{\mathrm{a}}$ and Brian A. Willis ${ }^{\mathrm{a}}$ \\ ${ }^{a}$ Eli Lilly and Company, Indianapolis, IN, USA \\ ${ }^{\mathrm{b}}$ Avid Radiopharmaceuticals, a Wholly Owned Subsidiary of Eli Lilly and Company, Indianapolis, IN, USA
}

Accepted 26 March 2021

Pre-press 19 April 2021

\begin{abstract}
.
Background: LY3202626 is a small molecule inhibitor of $\beta$-site amyloid precursor protein cleaving enzyme (BACE)1 shown to reduce amyloid- $\beta(A \beta)_{1-40}$ and $A \beta_{1-42}$ concentrations in plasma and cerebrospinal fluid developed for the treatment of Alzheimer's disease (AD).

Objective: To assess the change from baseline in flortaucipir positron emission tomography (PET) after treatment with LY3202626 compared with placebo in patients with mild AD dementia.

Methods: Patients received daily $3 \mathrm{mg}$ or $12 \mathrm{mg}$ doses of LY3202626 or placebo for 52 weeks. The primary outcome was assessment of cerebral neurofibrillary tangle load by flortaucipir PET. The study was terminated early following an interim analysis due to a low probability of identifying a statistically significant slowing of cognitive and/or functional decline.

Results: A total of 316 patients were randomized and 47 completed the study. There was no statistically significant difference between placebo and either dose of LY3202626 from baseline to 52 weeks, or in annualized change for flortaucipir PET. There was no clinically meaningful difference between placebo and LY3202626 doses on efficacy measures of cognition and function. No deaths or serious adverse events considered related to LY3202626 were reported. A statistically significant increase in treatment-emergent adverse events in the psychiatric disorders system organ class was reported for both LY3202626 doses compared to placebo.

Conclusion: LY3202626 tested at doses generating 70-90\% BACE inhibition was generally well tolerated in this study. LY3202626 treatment did not result in a clinically significant change in cerebral tau burden as measured by flortaucipir nor in change of functional or cognitive decline compared to placebo.
\end{abstract}

Trial registration: NCT02791191

Keywords: Alzheimer's disease, amyloid, neurofibrillary tangles, positron-emission tomography, tau

\section{INTRODUCTION}

Alzheimer's disease (AD) is a progressive degenerative neurological disorder that results in the slow

\footnotetext{
${ }^{*}$ Correspondence to: Albert C. Lo, MD, PhD, Eli Lilly and Company, Lilly Corporate Center, Indianapolis, IN 46285, USA. Tel.: +1 317209 4428; E-mail: albert.lo@lilly.com.
}

decline of cognition and function with a characteristic symptom of memory loss [1]. There is an unmet need for disease-modifying treatments in $\mathrm{AD}$, as currently available therapies are symptomatic and do not affect the underlying disease pathology.

Patients with AD display severe brain atrophy with neurofibrillary tangles and amyloid plaques at autopsy [2]. The definitive etiology and cause of AD 
are still poorly understood; however, there is evidence supporting the 'amyloid hypothesis' that amyloid$\beta$ (A $\beta$ ) peptides aggregate to form amyloid plaques which act as an initial trigger of $\mathrm{AD}[3]$. $\mathrm{A} \beta$ plaques have demonstrated neuronal toxicity and are hypothesized to lead to synapse loss, neurofibrillary tangle formation, and eventual neuronal cell death. The inhibition of $A \beta$ formation is therefore a logical strategy towards developing a therapy for AD.

$A \beta$ is part of the amyloid- $\beta$ protein precursor $(A \beta$ $\mathrm{PP}$ ), which is a transmembrane protein widely expressed on the cell surface, particularly in neurons. A $\beta P P$ has been found to be cleaved through two cleavage pathways involving three secretase enzymes: $\alpha$-secretase, $\gamma$-secretase, and $\beta$-secretase (now called $\beta$-site APP-cleaving enzyme [BACE]1). Cleavage of $A \beta P P$ by $\alpha$-secretase precludes the formation of $A \beta$ as the site is located within the $A \beta$ sequence. In the second pathway, $\beta$-secretase cleaves the A $\beta P P$ molecule, generating membrane-associated $\mathrm{C} 99$ and releasing a larger secreted fragment called secreted A $\beta P P$. Next, $\gamma$-secretase cleaves C99 in a heterogeneous fashion within the membrane releasing a variety of species that aggregate in protofibrils, and then fibrils, which seem to comprise the mass of $A \beta$ plaques in AD brain tissue [4]. While both $\gamma$ - and $\beta$-secretase inhibition represent effective means of precluding the formation of $\mathrm{A} \beta$, BACE inhibition may provide improved safety and tolerability.

The accumulation of aggregated tau protein in the brains of patients with $\mathrm{AD}$ is also a characteristic pathology associated with the disease. The density and neuroanatomical localization of tau neurofibrillary tangles correlate strongly with neurologic symptoms and AD progression [5]. The recent development of the $\left[{ }^{18} \mathrm{~F}\right] \mathrm{AV}-1451$ (flortaucipir) positron emission topography (PET) tracer allows for the ability to detect and measure tau protein in the brains of patients with suspected diagnosis of AD [6]. Use of this tracer shows increasing tau accumulation signal in healthy controls compared to mild cognitive impairment with progressive increases in patients with mild and moderate AD. The anatomical distribution seen on PET imaging corresponds well to the histopathological staging of Braak and Braak [7, 8]. Markers of tau pathology have also been shown to correlate more closely with changes in patient cognition compared to $A \beta$ markers [9-11].

LY3202626 is a synthetic small molecule potent oral BACE1 inhibitor developed for the treatment of AD dementia. LY3202626 has been shown to reduce plasma and cerebrospinal fluid (CSF) $A \beta_{1-40}$ and
$A \beta_{1-42}$ in mice, dogs, and humans. A Phase I study investigated the safety, tolerability, pharmacokinetics (PK), and pharmacodynamics (PD) of single- and multiple-ascending doses of LY3202626 given orally, in healthy subjects and patients with $\mathrm{AD}$. In this study, single and multiple doses of LY3202626 were well tolerated and demonstrated a robust, prolonged reduction in plasma $\mathrm{A} \beta$ concentrations [12].

In the setting of a number of BACE inhibitors undergoing clinical development at the same time, a Phase II proof-of-concept clinical development approach was taken to estimate the extent to which LY 3202626 impacted disease progression, and to better understand the mechanism of action of BACE inhibition on neurodegeneration biomarkers prior to initiating a Phase III program. The Phase II study (NAVIGATE-AD) aimed to assess whether suppression of $A \beta$ production in the brain by LY3202626 inhibition of the BACE1 enzyme could slow the progression of $\mathrm{AD}$ tau progression as assessed by PET imaging and AD progression as assessed by clinical outcome measures. This Phase II study prioritized high levels of enzyme inhibition (expected 70-90\% inhibition). Flortaucipir PET scans were chosen as the primary outcome endpoint for efficacy as a means to assess for cerebral tau neurofibrillary tangle load, a pathology known to correlate highly with cognition.

\section{MATERIALS AND METHODS}

\section{Patient population}

Patients were eligible for enrollment in the study if they were between 55 and 85 years of age, with mild AD dementia and evidence of amyloid pathology (as confirmed by National Institute on Aging - Alzheimer's Association disease diagnostic criteria and florbetapir PET scan, respectively $[13,14]$. Eligibility criteria included a score of 20 to 26 inclusive on the Mini-Mental-State Examination (MMSE), absence of significant neurological disease affecting the central nervous system (other than $\mathrm{AD}$ ) that may have affected cognition or the ability to complete the study, absence of ocular pathology that significantly limited the ability to evaluate vision or the retina, and having no history of use of strong inducers of cytochrome P450 3A.

\section{Study design}

The study was conducted at 76 centers in four countries from June 16, 2016 through July 2, 2018. 
The study consisted of a double-blind, randomized, placebo-controlled, 52-week treatment period comparing two fixed dose levels ( 3 and $12 \mathrm{mg}$ ) of LY 3202626 with placebo. The dose levels used were selected based on data from central and peripheral pharmacokinetic (PK) and pharmacodynamic (PD) data from single and multiple-dose studies in healthy subjects and patients with $\mathrm{AD}$, which were used to estimate the exposure required to reduce CSF $A \beta$ isoforms by $70-90 \%$ of baseline concentrations. Both strengths of LY3202626 and placebo capsules were visually identical. An interactive voice-response system randomly assigned patients according to a computer-generated assignment schedule. The NAVIGATE-AD trial was conducted in accordance with the ethical principles of the Declaration of Helsinki. Eligible patients provide written informed consent before undergoing study-related procedures. The trial protocol was approved by the institutional review board or ethics committee at each participating site. NAVIGATE-AD is registered at clinicaltrials.gov under the registration number NCT02791191.

\section{Assessments}

The primary outcome assessments were flortaucipir PET scans, which provide in vivo measurements of the anatomical distribution and load of paired helical filament-tau pathology in the brain [6]. The primary endpoint was the change in standardized uptake value ratio (SUVr) of flortaucipir from baseline and to 52 weeks after treatment.

Secondary evaluations of clinical efficacy included the assessment of cognition using the 13-item cognitive subscale of the AD Assessment Scale (ADAS$\operatorname{cog}_{13}$, with higher scores indicating worse function) [15], assessment of function using the AD Cooperative Study Activities of Daily Living Inventory instrumental subscale (ADCS-iADL, with lower scores indicating worse function) [16, 17], and assessment of composite cognition and function using the Integrated AD Rating Scale (iADRS, with lower scores indicating greater impairment) [18].

The safety and tolerability of LY3202626 was evaluated using standard safety assessments (including reporting of adverse events [AEs], clinical laboratory tests, vital signs and 12-lead electrocardiogram measurements, and physical and neurological examinations), magnetic resonance imaging (MRI), assessment of Active Risk Identification and Analysis and emergent radiological findings, skin, and eye examinations, and administration of the Columbia Suicide Severity Rating Scale [19]. A prespecified safety interim analysis was conducted by an assessment committee external to the study including an ophthalmology expert independent of the central readers and ophthalmologists used at study sites.

Exploratory outcomes included evaluation of cognition, function, neuropsychiatric symptoms, and subjective quality of life assessed by administration of the Montreal Cognitive Assessment (MoCA) [20], MMSE [21], Functional Activities Questionnaire (FAQ) [22, 23], and Everyday Cognition (ECog) [24], Neurospsychiatric Inventory (NPI) [25], and Bath Assessment of Subjective Quality of Life in Dementia (BASQID) [26] measures, respectively.

Exploratory assessments of biomarkers included assessment of change from baseline in brain amyloid and regional cerebral blood flow by florbetapir F18 PET scan, and brain regional volume following volumetric MRI scanning.

\section{Pharmacokinetics and pharmacodynamics}

Plasma samples were collected from patients to assess the PK of LY3202626 and the PD effects of treatment on levels of $A \beta$. Plasma samples obtained during this study were analyzed for LY3202626 using a validated liquid chromatography mass spectrometry method at Covance Bioanalytical Services, LLC (Indianapolis, IN, USA).

The $\mathrm{PK}$ analysis was undertaken using a population PK approach with the nonlinear mixed effects modeling program NONMEM version 7.4.2 on a computer that exceeded the minimum system requirements for this program. Perl Speaks NONMEM version 4.7.0 and Pirana version 2.9.1 were used for comparing models, conducting the bootstrap analysis, and generating the visual predictive check.

A 2-compartment model was used to fit the data, as this model was found to best approximate the concentration-time profile in a previous study. Normal Wishart priors were incorporated into the model to help stabilize the population parameter estimates, using parameter estimates and the covariance matrix from a model developed using an earlier study. Inter-subject and inter-occasion variability parameters were investigated. The final model was selected based upon objective function value, precision of parameter estimates, and the ability of the model to replicate the observed spread of the data. Model validation was conducted using the bootstrap and visual predictive check routines in Perl Speaks NONMEM. 


\section{Pharmacodynamic analyses}

Plasma $A \beta$ levels were measured using INNOBIA $^{\mathrm{TM}}$ plasma A $\beta$ forms (Fujirebio Product \# 81578). Change from baseline at the last treatment visit was calculated for both $A \beta_{1-40}$ and $A \beta_{1-42}$.

\section{Flortaucipir PET scans}

Flortaucipir scans were acquired once at screening and again following 52 weeks of treatment or at early discontinuation from the study. The change in composite SUVr [8] between baseline and follow-up scans was compared across treatment groups and to total exposure to LY3202626.

\section{Florbetapir PET scans}

Florbetapir scans were acquired twice. The first scan was acquired at screening and used for inclusion criteria and a second scan was obtained following 52 weeks of treatment or at early discontinuation from the study. The change in composite SUVr [8] between baseline and follow-up scans was compared across treatment groups and to total exposure to LY3202626.

An additional acquisition starting at the time of florbetapir administration generated a perfusion (or blood flow) map of the brain. In $\mathrm{AD}$, cerebral perfusion is reduced, especially in temporal and parietal areas, and this pattern of hypoperfusion closely mirrors the hypometabolism pattern observed using 18F-fluorodeoxyglucose-PET [27]. Changes in florbetapir perfusion PET between the baseline and follow-up scans were compared across treatment groups and to total exposure to LY3202626.

\section{Volumetric magnetic resonance imaging (vMRI)}

The vMRI scans were processed by tensorbased morphometry and parcellated using FreeSurfer. Changes in brain volume in twelve structures of interest from baseline to after 52 weeks of treatment (or early discontinuation) were quantified. Measurements of brain structural changes were evaluated and compared across treatment arms.

\section{Neurofilament light chain (NfL) measurement}

Ethylenediamine tetraacetic acid plasma samples were subjected to NfL measurement using Simoa NFlight assay kit (Quanterix, Billerica, MA, USA) on an HD-1 platform (Covance, Monogram Biosciences,
San Francisco, CA, USA). Plasma were diluted at $1: 4$ and measured in duplicate. Values were presented as $\mathrm{pg} / \mathrm{mL}$.

\section{Statistical analysis}

All analyses followed the intent-to-treat principle unless otherwise specified. The efficacy analysis population comprised all randomized participants who took at least one dose of double-blind study treatment and had at least one post-dose efficacy measurement. A priori, all tests of treatment effects of biological efficacy or clinical efficacy were conducted at a 1 -sided $\alpha=0.10$ (2-sided significance level of 0.2 ), unless otherwise stated. Safety assessments were conducted at a 2 -sided $\alpha=0.05$. As prespecified analyses, change from baseline analyses include subjects with both a baseline and a post-baseline measure. Due to early termination, this prespecified analysis was limited by the number of completers. In order to use all the data available and to facilitate comparability between groups over a standard period of time, change data was extrapolated to create an annualized outcome. Annualized change assumes linear change over time and was used to normalize the duration for change.

Sample size calculation was based on studies of longitudinal changes in flortaucipir PET SUVr data [8]. The a priori sample size of approximately 141 subjects with data post-randomization would have provided a statistical power of $85 \%$ to detect the chosen effect size of 0.28 , corresponding to a $50 \%$ slowing of progression (assuming an annualized change of 0.05 [standard deviation 0.09]), and using a one-sided test of $10 \%$ significance level.

Analysis of covariance (ANCOVA) was used to evaluate change in the primary endpoint flortaucipir SUVr from baseline at 52 weeks post-dose. The ANCOVA model included the fixed, categorical effects of treatment dose, and the continuous, fixed covariate of baseline flortaucipir SUVr and age at baseline. A similar ANCOVA model was used to analyze other biomarker imaging outcomes such as florbetapir perfusion PET and vMRI. In addition, annualized change in imaging biomarkers (florbetapir, flortaucipir, and vMRI) for each patient was calculated using the change at the last post-baseline visit. The annualized change was compared among the treatment groups with the same ANCOVA model described above. Annualized change assumes linear change over time and was used to normalize the duration for change and allow direct comparison 
between arms. As a post-hoc analysis for cerebral perfusion, annualized change was calculated from baseline to completion of the study or to the time of early discontinuation. A post-hoc analysis for change from baseline in vMRI, an ANCOVA model using treatment, between scan time, baseline, and age as covariates was also conducted. Clinical and functional outcome measurements (e.g., ADAS-Cog13, ADCS-iADL, iADRS, MoCA, FAQ, MMSE, ECog) were analyzed using a mixed-effect model for repeated measures which included fixed effect of treatment, visit, treatment-by-visit interaction, baseline age, baseline score, and baseline-by-visit interaction. Clinical outcome measurements such as NPI and BASQID used an ANCOVA model using treatment, baseline value, and age as covariates.

\section{RESULTS}

The trial was terminated early following an interim data analysis concluding that there was a low likelihood of identifying a statistically significant effect of LY3202626 in slowing functional or cognitive decline. At the point of early termination, 1,149 patients had been screened, 316 patients randomized, and 47 patients (14.9\%) had completed the study. The planned randomization ratio of $1: 1: 1$ to the $3 \mathrm{mg} /$ day, $12 \mathrm{mg} /$ day, and placebo arms was also altered, with randomization to the $3 \mathrm{mg}$ arm stopped after enrollment of 55 subjects in order to prioritize investigation of the higher LY3202626 dose in response to negative clinical efficacy data regarding other BACE inhibitors [28-30]. Patient disposition is summarized in Fig. 1.

At baseline, patient demographics were similar across the treatment arms (Table 1). The mean patient age was 72.9 years, with the majority of the treatment population being female $(60.8 \%)$, white $(82.9 \%)$, and from the United States (74.1\%). One patient was randomized but did not receive study drug. A total of 269 patients $(85.1 \%)$ discontinued from the study, with the most common reason for early discontinuation being the termination of the study by the sponsor (Fig. 1).

\section{Analysis of efficacy endpoints}

\section{Flortaucipir PET measurements}

As the study terminated early, the number of evaluable patients in each arm for the primary analysis was limited to 11,15 , and 15 patients in the placebo, $3 \mathrm{mg}$, and $12 \mathrm{mg}$ arms, respectively.

Neither of the LY3202626 arms demonstrated a statistically significant separation from the placebo arm in change from baseline to 52 weeks for flortaucipir PET measurement. The least-squares (LS) mean changes were 0.02 for the $3 \mathrm{mg}$ and 0.03 for the $12 \mathrm{mg}$ arm in comparison to 0.00 for placebo. A similar lack of significant change was observed following the calculation of annualized change from baseline to completion or early termination of the study (Fig. 2).

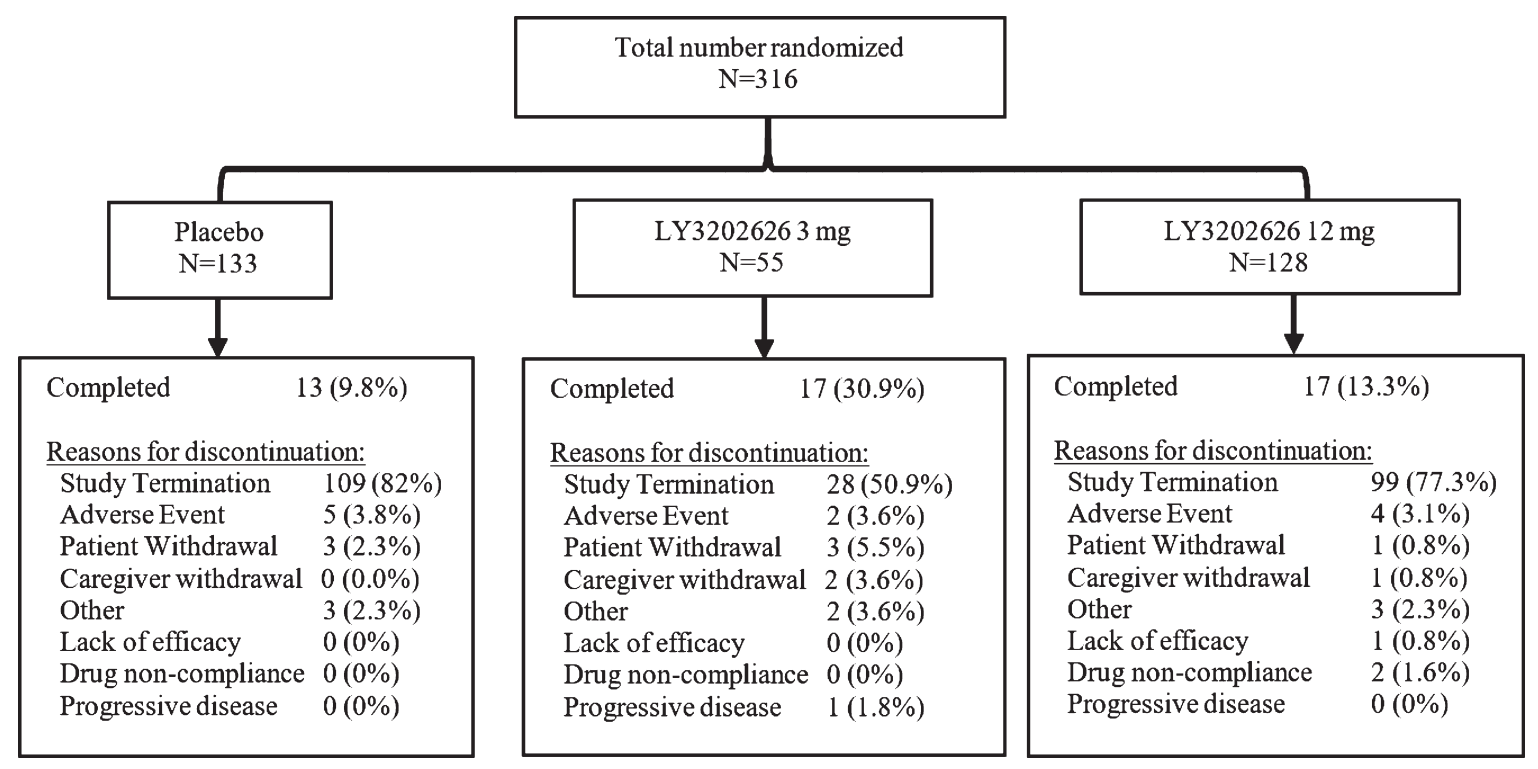

Fig. 1. Summary of patient disposition. 
Table 1

Summary of patient demographics

\begin{tabular}{|c|c|c|c|c|}
\hline & $\begin{array}{l}\text { Placebo } \\
(N=133)\end{array}$ & $\begin{array}{l}\text { LY3202626 } 3 \mathrm{mg} \\
(N=55)\end{array}$ & $\begin{array}{l}\text { LY3202626 12 mg } \\
\qquad(N=128)\end{array}$ & $\begin{array}{c}\text { Total } \\
(N=316) \\
\end{array}$ \\
\hline \multicolumn{5}{|l|}{$\overline{\text { Age }}$} \\
\hline$<65$ years old & $22(16.5)$ & $4(7.3)$ & $21(16.4)$ & $47(14.9)$ \\
\hline$\geq 65$ years old & $111(83.5)$ & $51(92.7)$ & $107(83.6)$ & $269(85.1)$ \\
\hline \multicolumn{5}{|l|}{$\operatorname{Race}(\mathrm{n}, \%)$} \\
\hline Asian & $13(9.8)$ & $8(14.5)$ & $18(14.1)$ & $39(12.3)$ \\
\hline Black or African American & $4(3.0)$ & $1(1.8)$ & $5(3.9)$ & $10(3.2)$ \\
\hline $\begin{array}{l}\text { Native Hawaiian or other } \\
\quad \text { Pacific Islander }\end{array}$ & $1(0.8)$ & $1(1.8)$ & $0(0.0)$ & $2(0.6)$ \\
\hline White & $113(85.0)$ & $45(81.8)$ & $104(81.3)$ & $262(82.9)$ \\
\hline Multiple & $2(1.5)$ & $0(0.0)$ & $1(0.8)$ & $3(0.9)$ \\
\hline \multicolumn{5}{|l|}{ Ethnicity } \\
\hline Hispanic or Latino & $7(5.3)$ & $1(1.8)$ & $5(3.9)$ & $13(4.1)$ \\
\hline Not applicable & $13(9.8)$ & $4(7.3)$ & $15(11.7)$ & $32(10.2)$ \\
\hline Not Hispanic or Latino & $112(84.8)$ & $50(90.9)$ & $108(84.4)$ & $270(85.7)$ \\
\hline \multicolumn{5}{|l|}{ Weight $(\mathrm{kg})$} \\
\hline Mean (SD) & $74.3(16.2)$ & $72.8(18.3)$ & $69.5(16.2)$ & $72.1(16.6)$ \\
\hline \multicolumn{5}{|l|}{ BMI $\left(\mathrm{kg} / \mathrm{m}^{2}\right)$} \\
\hline Mean $(S D)$ & $26.9(5.0)$ & $25.9(5.1)$ & $25.6(5.0)$ & $26.2(5.0)$ \\
\hline \multicolumn{5}{|l|}{$A P O E 4$ carrier status $^{\mathrm{a}}$} \\
\hline No & $36(27.5)$ & $13(24.5)$ & $40(31.7)$ & $89(28.7)$ \\
\hline Yes & $95(72.5)$ & $40(75.5)$ & $86(68.3)$ & $221(71.3)$ \\
\hline \multicolumn{5}{|l|}{ Country } \\
\hline Australia & $15(11.3)$ & $5(9.1)$ & $23(18.0)$ & 43 (13.6) \\
\hline Canada & $1(0.8)$ & $0(0.0)$ & $1(0.8)$ & $2(0.6)$ \\
\hline Japan & $12(9.0)$ & $7(12.7)$ & $18(14.1)$ & $37(11.7)$ \\
\hline United States & 105 (78.9) & $43(78.2)$ & $86(67.2)$ & $234(74.1)$ \\
\hline
\end{tabular}

APOE4, apolipoprotein E4; BMI, body mass index; SD, standard deviation. ${ }^{\text {a } D a t a ~ m i s s i n g ~ f o r ~} 2$ patients in each treatment group.

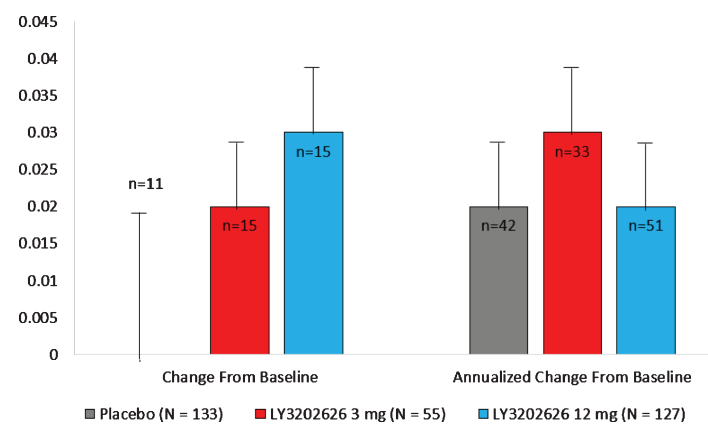

Fig. 2. LS mean (SE) change from baseline and annualized change from baseline in flortaucipir SUVr. LS, least-squares; N, number of subjects in the analysis population; $n$, number of subjects who contributed data both at baseline and at specified visit; SE, standard error; SUVr, standardized uptake value ratio. Note: Annualized change was calculated by extrapolating observed change based on time between scans.

Measures of cognition, function, quality of life, and neuropsychiatric symptoms

No clinically meaningful separation was observed between the LY3202626 arms and placebo in the analysis of secondary efficacy measures of cognition, function, and composite measures of cognition and function (ADAS-Cog ${ }_{13}$, ADCS-iADL, and iADRS, respectively) following 52 weeks of treatment (Fig. 3). Some spurious statistically significant differences were observed in iADL and iARDS scores following 52 weeks of treatment; however, these findings should be interpreted with caution due to the limited sample size at 52 weeks following early termination of the study. These secondary analyses were not adjusted for multiplicity. There was no clinically meaningful separation between the LY3202626 arms and placebo in the exploratory efficacy measures of cognition, function, subjective quality of life, and neuropsychiatric symptoms (MoCA and MMSE; FAQ and ECog; BASQID; and NPI, respectively) (Fig. 4) after 52 weeks of treatment. At the significance level of 0.2 , there were few seemingly spurious statistically significant changes for both LY3202626 arms in ECog global score and NPI total score at Week 52; however, these results should be interpreted with caution due to the limited sample sizes.

\section{Exploratory outcomes: vMRI, cerebral perfusion, florbetapir, and NfL}

Effect on brain volume. vMRI treatment comparisons of regional brain volume changes were conducted using the following three statistical 


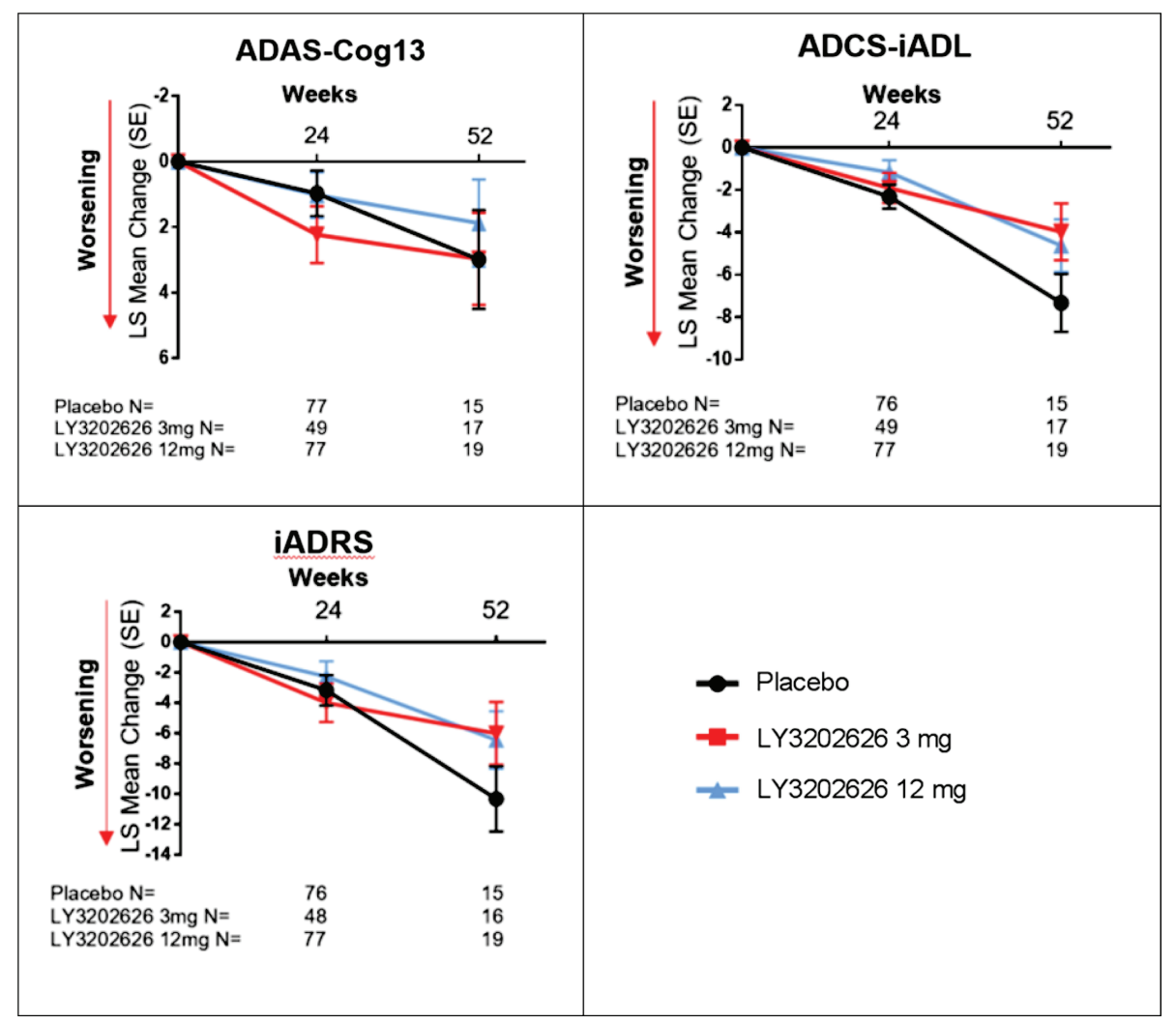

Fig. 3. LS mean (SE) change from baseline on ADAS-Cog13, ADCS-iADL, and iADRS. ADAS-Cog13, Alzheimer Disease Assessment Scale-cognitive subscale; ADCS-iADL, Alzheimer's Disease Cooperative Study-Instrumental Activities of Daily Living Inventory; iADRS, Integrated Alzheimer's Disease Rating Scale; LS, least-squares; SE, standard error.

approaches within the ANCOVA model (the first two were defined a priori in the protocol and the third was added as a consequence of early termination): 1) change from baseline to 52 weeks as outcome, with treatment, age, and baseline as covariates; 2) annualized change as outcome, with treatment, age, and baseline as covariates; and 3) change from baseline to last observation as outcome, with treatment, age, baseline, and between-time scan as covariates. The first analysis, which compared measurements at baseline and 52 weeks, had the fewest number of patients (placebo [8/58]; LY3202626 $3 \mathrm{mg}$ [15/38]; LY3202626 $12 \mathrm{mg}$ [12/60]). The third analysis uses time between baseline to last scan as a covariate in the model to account for a last scan that may not have occurred at 52 weeks due to early discontinuation.

Volumes of twelve brain regions were analyzed. In summary, using any of the three statistical approaches, treatment differences in regional brain volume change (bilateral sum) with greater reduction seen in any dose of LY3202626 to placebo were seen in the following regions (overall $p$ for annualized change provided): entorhinal cortex $(p=0.044)$, hippocampus $(p=0.019)$, medial temporal lobe $(p=$ $0.021)$, lateral $(p=0.034)$ and inferior parietal lobes $(p=0.032)$, and isthmus of the cingulate gyrus $(p=$ 0.152 ). Using the annualized change analyses, no statistically significant volume difference for either LY3202626 dose to placebo in the following six brain regions was observed: whole brain, ventricles, whole temporal lobe, superior temporal lobe, prefrontal lobe, and precuneus (Fig. 5). Supplementary Table 1 presents all vMRI treatment comparisons of regional brain volume changes for each of the three analytical approaches described above.

Cerebral perfusion. Due to early study termination, the number of evaluable patients for the florbetapir PET cerebral perfusion analysis who reached 52 weeks was limited to 10,16 , and 9 patients in the placebo, $3 \mathrm{mg}$, and $12 \mathrm{mg}$ arms, respectively. No significant overall treatment effect (at 0.2 significance level) was observed using the perfusion SUVr methodologies applied. The LS mean changes were: -0.05 for the $3 \mathrm{mg}$ arm, -0.03 for the $12 \mathrm{mg}$ arm, 


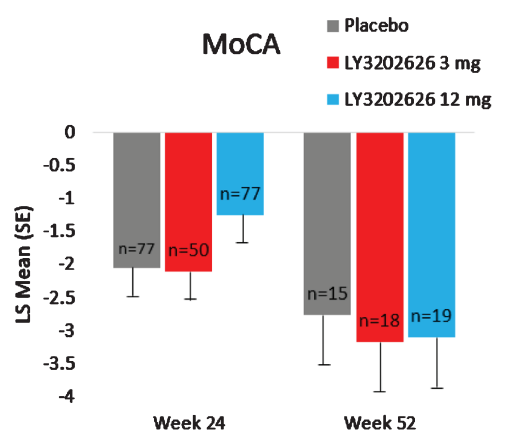

ECog

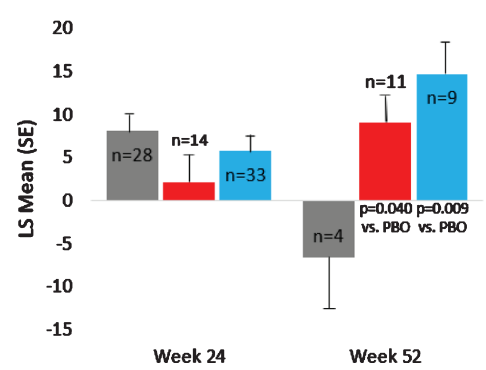

FAQ

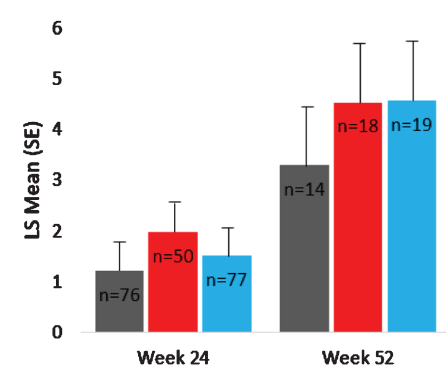

NPI
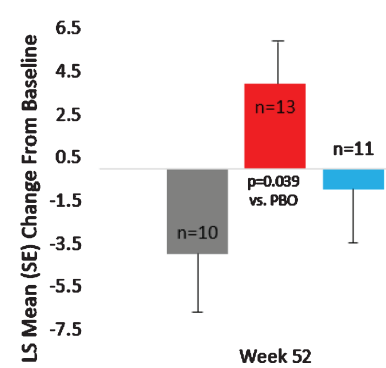

Fig. 4. Exploratory efficacy endpoint analyses. Results presented are change from baseline. MoCA, FAQ, MMSE, and ECog assessment were analyzed using a mixed models repeated measures model. Baseline is defined as last observation before or at randomization. BASQID, Bath Assessment of Subjective Quality of Life in Dementia; ECog, Measurement of Everyday Cognition; FAQ, Functional Activities Questionnaire; LS, least-squares; MMSE, Mini-Mental State Examination; MoCA, Montreal Cognitive Assessment; NPI; Neuropsychiatric Inventory; PBO, placebo; SE, standard error.

in comparison to -0.03 for placebo. In the post-hoc annualized change analysis, there was reduced perfusion in the $12 \mathrm{mg}$ group compared to placebo $(p=0.009)$.

Florbetapir. The number of evaluable patients for the florbetapir PET analysis was limited to 10, 16, and 10 patients in the placebo, $3 \mathrm{mg}$, and $12 \mathrm{mg}$ arms, respectively. Neither of the LY3202626 doses had a statistically significant separation (at 0.2 significance level) from the placebo arm in change from baseline to 52 weeks for florbetapir PET measurements. The post-hoc annualized change analyses comparing each of the LY3202626 doses and placebo were not statistically significant.

Neurofilament light chain. NfL is a promising biomarker for measuring neurodegeneration. Plasma NfL levels were measured in 310 samples at baseline and 150 samples at post-baseline (111 samples at Week 36, and 39 samples at Week 52). Annualized changes were calculated by extrapolating last observed change based on time between data points. There was no statistically significant difference in the change of plasma NfL levels between placebo and the LY3202626 arms (Supplementary Table 2).

\section{Pharmacokinetic and pharmacodynamic assessments}

\section{Pharmacokinetics}

The PK of LY3202626 were assessed by analysis of a population PK model. It was originally intended to evaluate the effects of patient factors, such as age, on the PK of LY3202626; however, this was not completed due to the early termination of the study.

A two-compartment model was chosen for this analysis based upon previous models that demonstrated such a model to be most appropriate. Due to the limited amount of terminal phase data collected during the study, PK parameter estimates from a model developed with data from a single- and multiple-ascending dose study were incorporated as priors for this analysis. Final parameter estimates are presented in Table 2. 

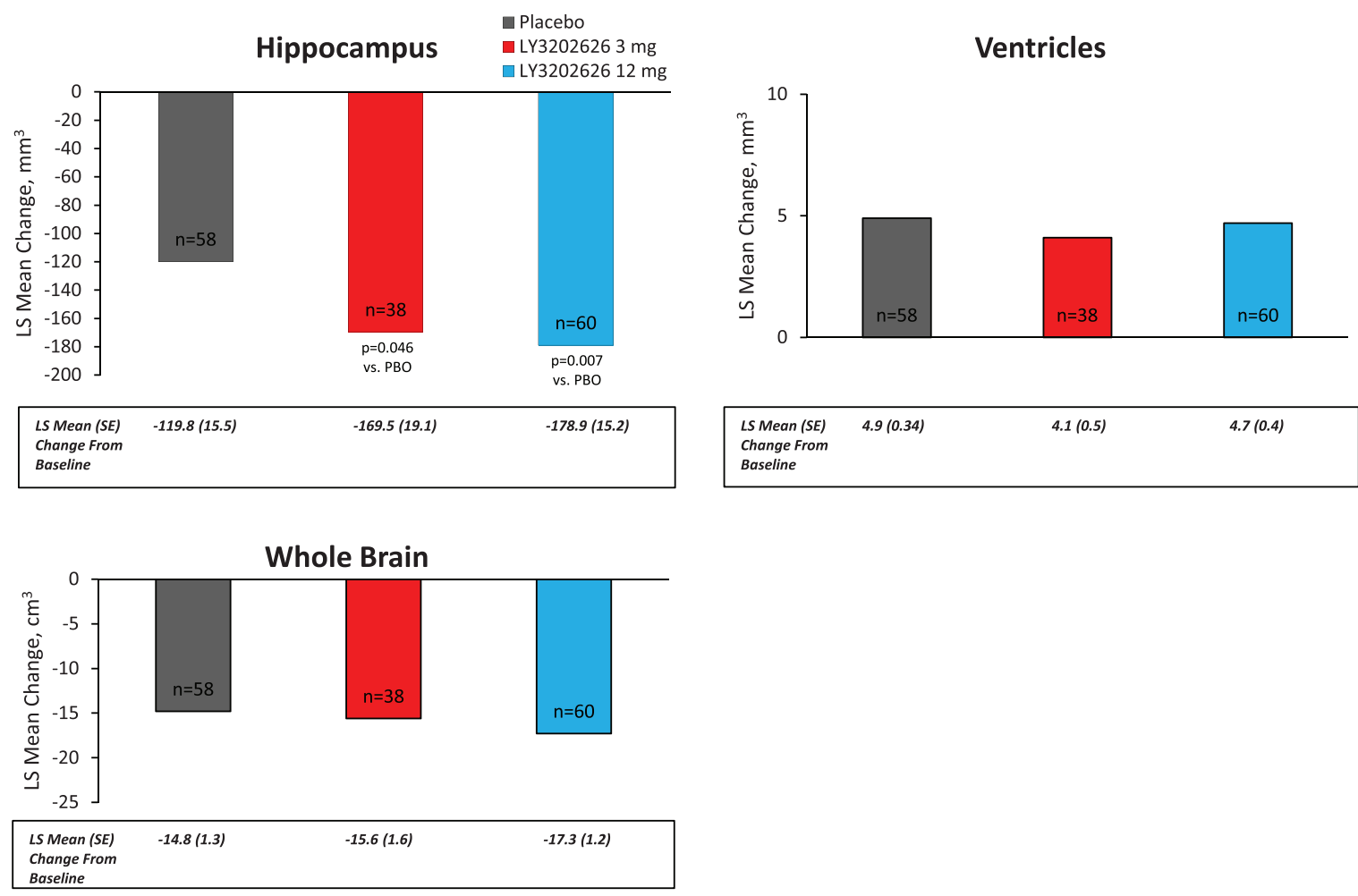

Fig. 5. Annualized LS mean change from baseline as measured by vMRI. LS, least-squares; PBO, placebo; SE, standard error; vMRI, volumetric magnetic resonance imaging.

Table 2

Population PK estimates

\begin{tabular}{|c|c|c|c|}
\hline $\begin{array}{l}\text { Parameter } \\
\text { Description }\end{array}$ & $\begin{array}{c}\text { Population } \\
\text { Estimate }(\% \mathrm{SEE}) \\
{[95 \% \mathrm{CI}]}\end{array}$ & $\begin{array}{c}\text { Inter-Subject } \\
{\text { Variability }(\% \mathrm{SEE})^{\mathrm{a}}}^{[95 \% \mathrm{CI}]}\end{array}$ & $\begin{array}{c}\text { Within-Subject } \\
\text { Variability }(\% \text { SEE })^{\mathrm{a}} \\
{[95 \% \mathrm{CI}]}\end{array}$ \\
\hline $\begin{array}{l}\text { Absorption rate constant (KA) } \\
\left(\mathrm{h}^{-1}\right)\end{array}$ & $\begin{array}{c}0.0333(4.8) \\
{[0.031,0.342]}\end{array}$ & $\begin{array}{l}30.2(66.2)^{\mathrm{b}} \\
{[29.7,59.4]}\end{array}$ & $\begin{array}{c}44.4(29.2)^{\mathrm{b}} \\
{[18.8,60.5]}\end{array}$ \\
\hline $\begin{array}{l}\text { Apparent oral clearance }(\mathrm{CL}) \\
(\mathrm{L} / \mathrm{h})\end{array}$ & $\begin{array}{l}20.0(4.2) \\
{[18.4,21.6]}\end{array}$ & $\begin{array}{l}62.1(12.0)^{\mathrm{b}} \\
{[54.8,69.3]}\end{array}$ & - \\
\hline $\begin{array}{l}\text { Central volume of distribution (V2) } \\
\text { (L) }\end{array}$ & $\begin{array}{c}51.9(9.3) \\
{[46.6,58.3]}\end{array}$ & $\begin{array}{l}156(21.4)^{\mathrm{b}} \\
{[81.4,162]}\end{array}$ & - \\
\hline $\begin{array}{l}\text { Intercompartmental clearance }(\mathrm{Q}) \\
\quad(\mathrm{L} / \mathrm{h})\end{array}$ & $\begin{array}{l}1.86(24.3) \\
{[1.40,2.42]}\end{array}$ & - & - \\
\hline $\begin{array}{l}\text { Peripheral volume of distribution (V3) } \\
\text { (L) }\end{array}$ & $\begin{array}{l}161(11.4) \\
{[148,176]}\end{array}$ & - & - \\
\hline $\begin{array}{l}\text { Bioavailability }(\mathrm{F} 1) \\
(\%)\end{array}$ & $\begin{array}{l}1.0 \text { (Fixed) } \\
{[\mathrm{NA}]}\end{array}$ & - & $\begin{array}{l}40.2(6.5)^{\mathrm{b}} \\
{[37.1,43.9]}\end{array}$ \\
\hline $\begin{array}{l}\text { Absorption lag time (ALAG) } \\
\text { (h) }\end{array}$ & $\begin{array}{l}0.39 \text { (Fixed) } \\
{[\mathrm{NA}]}\end{array}$ & - & - \\
\hline $\begin{array}{l}\text { Interaction term (CL and V2) } \\
\text { Residual Error }\end{array}$ & & $0.550(15.0)[\mathrm{NA}]$ & \\
\hline $\begin{array}{l}\text { Additive } \\
\text { Proportional }\end{array}$ & $\begin{array}{l}0.1 \text { (Fixed) [NA] } \\
19.0 \%(2.9)[\mathrm{NA}]\end{array}$ & & \\
\hline
\end{tabular}

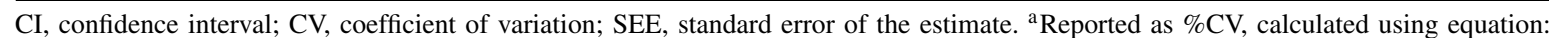
$100 \cdot \sqrt{e^{O M E G A(N)}-1}$, where OMEGA(N) is the NONMEM output for the inter-subject/within-subject variability of the Nth parameter. $\mathrm{b} \% \mathrm{SEE}$ for original variance estimate, not calculated $\% \mathrm{CV}$. 
Table 3

Assessment of plasma amyloid concentrations following LY3202626 dosing

\begin{tabular}{|c|c|c|c|c|c|c|}
\hline & \multicolumn{3}{|c|}{$\mathrm{A} \beta_{1-40}$} & \multicolumn{3}{|c|}{$\mathrm{A} \beta_{1-42}$} \\
\hline & $\begin{array}{c}\text { Baseline } \\
\text { Concentration } \\
(\mathrm{pg} / \mathrm{mL})^{a}\end{array}$ & $\begin{array}{l}\text { Last Treatment } \\
\text { Visit Concentration } \\
\quad(\mathrm{pg} / \mathrm{mL})^{a}\end{array}$ & $\begin{array}{c}\text { Change from } \\
\text { Baseline } \\
(\%)\end{array}$ & $\begin{array}{c}\text { Baseline } \\
\text { Concentration } \\
(\mathrm{pg} / \mathrm{mL})^{a}\end{array}$ & $\begin{array}{c}\text { Last Treatment } \\
\text { Visit Concentration } \\
\quad(\mathrm{pg} / \mathrm{mL})^{a}\end{array}$ & $\begin{array}{c}\text { Change from } \\
\text { Baseline } \\
(\%)\end{array}$ \\
\hline Placebo & $164.8(100.1)$ & $141.5(38.5)$ & -14.3 & $57.9(27.2)$ & $54.1(11.1)$ & -6.40 \\
\hline 3 mg LY3202626 & $173.4(124.1)$ & $24.6(29.8)$ & -85.8 & $57.8(36.2)$ & $18.4(9.8)$ & -68.1 \\
\hline $12 \mathrm{mg} \mathrm{LY} 3202626$ & $153.2(64.3)$ & $12.2(17.4)$ & -92.0 & $52.7(16.8)$ & $13.4(6.3)$ & -74.5 \\
\hline
\end{tabular}

$\mathrm{A} \beta$, amyloid- $\beta$ peptide. ${ }^{a}$ Reported as mean (standard deviation).

As the study terminated early, the impact of patient-specific factors and other covariates were not assessed. Based on a visual predictive check, the model appeared to adequately characterize the concentration-time profile, although minimum blood plasma concentration $\left(\mathrm{C}_{\min }\right)$ appeared to be slightly under-predicted (Supplementary Figure 1).

\section{Pharmacodynamic assessment of $A \beta$}

Plasma $A \beta_{1-40}$ and $A \beta_{1-42}$ concentrations were measured at various visits throughout the study. A comparison of $A \beta$ concentrations was made at baseline and at each patient's last visit on treatment. Plasma $A \beta$ concentrations were substantially reduced at both the $3 \mathrm{mg}$ and $12 \mathrm{mg}$ dose levels. A summary of plasma $A \beta_{1-40}$ and $A \beta_{1-42}$ concentrations at baseline and last visit are shown in Table 3 .

\section{Safety and tolerability}

The proportion of patients reporting $\geq 1$ treatment emergent adverse event (TEAE) was numerically greater in the two LY3202626 arms $(n=46,83.6 \%$ in the $3 \mathrm{mg}$ arm and $n=96,75.6 \%$ in the $12 \mathrm{mg}$ arm) than in the placebo arm $(n=91,68.4 \%)$; however, no statistically significant differences were observed overall. No trial participants died during the study, and $31(9.8 \%)$ patients reported a serious adverse event (SAE). The majority of SAEs resolved, and only one
SAE (suicidal ideation by a subject in the placebo arm) was reported as related to study treatment. A summary of reported AEs is shown in Table 4.

Most TEAEs were of mild severity. There were no statistically significant differences among treatment arms in the incidence of TEAEs classified as severe. There were no clinically significant findings in laboratory tests for chemistry parameters analyzed (observed values and changes from baseline), or in patients who had treatment-emergent abnormal laboratory values, between the LY3202626 arms and placebo.

A statistically significant increase in TEAEs in the psychiatric disorder system organ class was observed in both treatment arms compared to placebo (Table 5). There were no statistically significant differences between treatment arms in the number of patients with suicide-related treatment-emergent events based on the Columbia Suicide Severity Rating Scale, although a higher number of patients had treatmentemergent suicidal ideation in the LY3202626 $12 \mathrm{mg}$ arm. A statistically significantly greater proportion of patients in the LY3202626 $3 \mathrm{mg}$ arm compared to the placebo arm experienced the following events: muscle spasms, headache, anxiety, cough, and contact dermatitis.

No statistically or clinically significant differences in MRI findings or clinical laboratory assessments were noted.

Table 4

Overview of adverse events

\begin{tabular}{lcccc}
\hline $\begin{array}{l}\text { Number of } \\
\text { subjects } \\
(n, \%)\end{array}$ & Placebo & LY3202626 & LY3202626 & Total \\
$12 \mathrm{mg}$ & $(N=127)$ & $(N=315)$ \\
\hline $\begin{array}{l}\text { Deaths } \\
\text { Serious adverse events }\end{array}$ & $(N=133)$ & $(N=55)$ & $0(0.0)$ & $0(0.0)$ \\
$\begin{array}{l}\text { Discontinuations } \\
\quad \text { due to an AE }\end{array}$ & $0(0.0)$ & $0(0.0)$ & $10(7.9)$ & $31(9.8)$ \\
$\begin{array}{l}\text { TEAEs } \\
\text { TEAEs related to }\end{array}$ & $3(2.3)$ & $0(18.2)$ & $2(1.6)$ & $5(1.6)$ \\
$\quad$ study treatment & $91(68.4)$ & $46(83.6)$ & $96(75.6)$ & $233(74.0)$ \\
\hline
\end{tabular}

$\mathrm{AE}$, adverse event; $N$, number of subjects in analysis population; $n$, number of subjects with at least one adverse event per event type; TEAE, treatment-emergent adverse event. 
Table 5

Treatment-emergent adverse events occurring in $\geq 5 \%$ of treated patients by system organ class and preferred term

\begin{tabular}{|c|c|c|c|c|c|c|c|}
\hline & $\begin{array}{l}\text { Placebo } \\
(N=133)\end{array}$ & $\begin{array}{c}\text { LY3202626 } \\
3 \mathrm{mg}(N=55)\end{array}$ & $\begin{array}{c}\text { LY3202626 } \\
12 \mathrm{mg}(N=127)\end{array}$ & $\begin{array}{c}\text { Total } \\
(N=315)\end{array}$ & & $\begin{array}{l}\text { Pairwise } \\
p \text {-values }^{\text {a }}\end{array}$ & \\
\hline $\begin{array}{l}\text { System Organ Class } \\
\text { Preferred Term }\end{array}$ & $n(\%)$ & $n(\%)$ & $n(\%)$ & $n(\%)$ & $\begin{array}{l}\text { PBO versus } \\
\quad 3 \mathrm{mg}\end{array}$ & $\begin{array}{l}\text { PBO versus } \\
12 \mathrm{mg}\end{array}$ & $\begin{array}{c}3 \mathrm{mg} \text { versus } \\
12 \mathrm{mg}\end{array}$ \\
\hline Subjects with $>=1$ TEAE & $91(68.4)$ & $46(83.6)$ & $96(75.6)$ & $233(74.0)$ & 0.046 & 0.216 & 0.250 \\
\hline Cardiac disorders & $6(4.5)$ & $4(7.3)$ & $5(3.9)$ & $15(4.8)$ & 0.482 & 1.000 & 0.457 \\
\hline Atrial fibrillation & $1(0.8)$ & $3(5.5)$ & $1(0.8)$ & $5(1.6)$ & 0.076 & 1.000 & 0.083 \\
\hline Eye disorders & $12(9.0)$ & $9(16.4)$ & $15(11.8)$ & $36(11.4)$ & 0.201 & 0.544 & 0.475 \\
\hline Cataract & $1(0.8)$ & $3(5.5)$ & $1(0.8)$ & $5(1.6)$ & 0.076 & 1.000 & 0.083 \\
\hline Gastrointestinal disorders & $18(13.5)$ & $14(25.5)$ & $22(17.3)$ & $54(17.1)$ & 0.056 & 0.492 & 0.227 \\
\hline $\begin{array}{l}\text { General disorders and } \\
\text { administration site conditions }\end{array}$ & $15(11.3)$ & $7(12.7)$ & $23(18.1)$ & $45(14.3)$ & 0.805 & 0.160 & 0.514 \\
\hline Fatigue & $7(5.3)$ & $0(0.0)$ & $5(3.9)$ & $12(3.8)$ & 0.108 & 0.770 & 0.325 \\
\hline Infections and infestations & $34(25.6)$ & $23(41.8)$ & $39(30.7)$ & $96(30.5)$ & 0.036 & 0.408 & 0.174 \\
\hline Nasopharyngitis & $7(5.3)$ & $7(12.7)$ & $14(11.0)$ & $28(8.9)$ & 0.122 & 0.112 & 0.802 \\
\hline Upper respiratory tract infection & $7(5.3)$ & $5(9.1)$ & $6(4.7)$ & $18(5.7)$ & 0.338 & 1.000 & 0.312 \\
\hline Urinary tract infection & $3(2.3)$ & $3(5.5)$ & $7(5.5)$ & $13(4.1)$ & 0.361 & 0.208 & 1.000 \\
\hline $\begin{array}{l}\text { Injury, poisoning and } \\
\text { procedural complications }\end{array}$ & $20(15.0)$ & $14(25.5)$ & $21(16.5)$ & $55(17.5)$ & 0.099 & 0.865 & 0.218 \\
\hline Fall & $9(6.8)$ & $2(3.6)$ & $9(7.1)$ & $20(6.3)$ & 0.513 & 1.000 & 0.509 \\
\hline Contusion & $4(3.0)$ & $1(1.8)$ & $11(8.7)$ & $16(5.1)$ & 1.000 & 0.063 & 0.111 \\
\hline Skin abrasion & $2(1.5)$ & $3(5.5)$ & $1(0.8)$ & $6(1.9)$ & 0.150 & 1.000 & 0.083 \\
\hline Investigations & $11(8.3)$ & $8(14.5)$ & $13(10.2)$ & $32(10.2)$ & 0.196 & 0.670 & 0.451 \\
\hline $\begin{array}{l}\text { Metabolism and } \\
\text { nutrition disorders }\end{array}$ & $10(7.5)$ & $3(5.5)$ & $8(6.3)$ & $21(6.7)$ & 0.759 & 0.809 & 1.000 \\
\hline $\begin{array}{l}\text { Musculoskeletal and } \\
\text { connective tissue disorders }\end{array}$ & $19(14.3)$ & $10(18.2)$ & $17(13.4)$ & $46(14.6)$ & 0.511 & 0.859 & 0.496 \\
\hline Arthralgia & $8(6.0)$ & $2(3.6)$ & $4(3.1)$ & $14(4.4)$ & 0.726 & 0.378 & 1.000 \\
\hline Muscle spasms & $1(0.8)$ & $4(7.3)$ & $0(0.0)$ & $5(1.6)$ & 0.026 & 1.000 & 0.008 \\
\hline Nervous system disorders & $16(12.0)$ & $12(21.8)$ & $23(18.1)$ & $51(16.2)$ & 0.114 & 0.224 & 0.547 \\
\hline Headache & $2(1.5)$ & $5(9.1)$ & $4(3.1)$ & $11(3.5)$ & 0.024 & 0.438 & 0.132 \\
\hline Psychiatric disorders & $13(9.8)$ & $12(21.8)$ & $29(22.8)$ & $54(17.1)$ & 0.034 & 0.006 & 1.000 \\
\hline Anxiety & $0(0.0)$ & $3(5.5)$ & $4(3.1)$ & $7(2.2)$ & 0.024 & 0.056 & 0.433 \\
\hline Confusional state & $1(0.8)$ & $3(5.5)$ & $3(2.4)$ & $7(2.2)$ & 0.076 & 0.361 & 0.369 \\
\hline Insomnia & $1(0.8)$ & $3(5.5)$ & $0(0.0)$ & $4(1.3)$ & 0.076 & 1.000 & 0.027 \\
\hline $\begin{array}{l}\text { Renal and urinary } \\
\text { disorders }\end{array}$ & $3(2.3)$ & $4(7.3)$ & $6(4.7)$ & $13(4.1)$ & 0.197 & 0.325 & 0.493 \\
\hline $\begin{array}{l}\text { Respiratory, thoracic and } \\
\text { mediastinal disorders }\end{array}$ & $6(4.5)$ & $8(14.5)$ & $12(9.4)$ & $26(8.3)$ & 0.029 & 0.145 & 0.313 \\
\hline Cough & $2(1.5)$ & $6(10.9)$ & $5(3.9)$ & $13(4.1)$ & 0.008 & 0.273 & 0.091 \\
\hline $\begin{array}{l}\text { Skin and subcutaneous } \\
\text { tissue disorders }\end{array}$ & $18(13.5)$ & $11(20.0)$ & $18(14.2)$ & $47(14.9)$ & 0.274 & 1.000 & 0.379 \\
\hline Dermatitis contact & $1(0.8)$ & $5(9.1)$ & $1(0.8)$ & $7(2.2)$ & 0.009 & 1.000 & 0.010 \\
\hline $\begin{array}{l}\text { Surgical and medical } \\
\text { procedures }\end{array}$ & $6(4.5)$ & $8(14.5)$ & $9(7.1)$ & $23(7.3)$ & 0.029 & 0.432 & 0.163 \\
\hline Vascular disorders & $6(4.5)$ & $3(5.5)$ & $8(6.3)$ & $17(5.4)$ & 0.722 & 0.590 & 1.000 \\
\hline
\end{tabular}

$N$, number of subjects in analysis population; $n$, number of subjects with treatment-emergent adverse event; PBO, placebo; TEAE, treatmentemergent adverse event. ${ }^{a} p$-values for pairwise treatment comparisons were computed using FISHER test.

The study of non-clinical toxicology results revealed potential toxicity and pathology at the retinal pigment epithelial layer; therefore, eye disorders were identified as AEs of special interest. An ophthalmology visit was added to the protocol for visual and retinal assessments including visual acuity, intraocular pressure, dilated fundoscopic exam, slit lamp exam, color photography of the retina, and optical coherence tomography. As shown in Table 5, no statistically significant increase in TEAEs in the eye disorder system organ class was observed in either treatment arm compared to placebo and no clinically significant pattern of eye TEAEs were noted in this study. There was no clinically meaningful difference in visual acuity (Supplementary Figure 2), retinal thickness grid (Supplementary Figure 3), or optic nerve head pathology between treatment arms and placebo. Initial data from the study site's ophthalmologists indicated a statistically significant increased incidence of changes in the optic nerve head in 
both LY3202626 arms versus placebo at any time ( $p$ for overall treatment effect $=0.005$ ). This finding required further evaluation which subsequently did not confirm an increased incidence of optic nerve head changes (see below). Furthermore, the summary of changes from baseline of ophthalmic coherence tomography (OCT) evaluation did not show any clinically meaningful differences.

The treatment-emergent fundus photography evaluation showed areas of new or worsened drusen that were statistically different between LY3202626 and placebo at any visit time point (overall comparison $p=0.043$ ). Drusen changes further evaluated in shift tables (change toward worsening, change toward improving, or no change) showed no clinically significant patterns.

Because of the potential clinical importance, the specific images labeled with hemorrhage and the OCT data were further evaluated with the study's central external ophthalmology expert in order to adjudicate the hemorrhages and better understand any pattern for retinal volume changes. This review did not verify the presence of optic nerve head hemorrhages in three of the four cases and did not note any change in the optic nerve head specifically in the three cases of worsening identified in the prior site examination. Moreover, no consistent OCT volume patterns for change or visual acuity changes were confirmed (Supplementary Figures 2 and 3).

\section{DISCUSSION}

This Phase II study prioritized the testing of high BACE1 inhibition (70-90\% inhibition of CSF A $\beta$, $3 \mathrm{mg}$ and $12 \mathrm{mg}$ of LY3202626 daily, respectively) over 52 weeks for the reduction disease progression in patients with mild AD dementia and confirmed amyloid pathology. This proof-of-concept study included a number of biomarkers aimed at understanding the effect of BACE inhibition on downstream neurodegenerative pathology and changes (e.g., flortaucipir, $\mathrm{NfL}, \mathrm{vMRI}$ ) and their relation to clinical outcomes of efficacy and safety. The study was stopped early, after an interim analysis was added, due to potential safety concerns emerging from the clinical trial results of other BACE inhibitors. The interim analysis was added to assess potential worsening of clinical outcomes as a consequence of treatment with a BACE inhibitor (as reported in other studies of BACE inhibitor compounds) and to evaluate futility. As a result of early termination, there were a limited number of patients who fully completed the study or even reached a later assessment visit. In examination of enrolled patients using prespecified and additional statistical analyses, treatment with BACE1 inhibitor LY3202626 did not slow disease progression (as assessed by flortaucipir PET scan) or reduce the clinically significant decline in cognition or function, as compared with placebo.

Another consideration in interpreting the negative results of this study is the appropriateness of the administered dose. As discussed previously, the study randomization was altered to prioritize investigation of the $12 \mathrm{mg}$ daily dose following reports of negative clinical efficacy outcomes regarding another BACE inhibitor [29]. Treatment with the $3 \mathrm{mg}$ dose of LY3202626 reduced the concentrations of $A \beta_{1-40}$ and $A \beta_{1-42}$ by $85.8 \%$ and $68.1 \%$ from baseline, respectively, which confirms that the drug had the intended PD effect of reducing the production of $A \beta$. Finally, the mild AD population enrolled may have been too far along in their disease process to respond to a BACE inhibitor treatment. A BACE inhibitor trial was terminated in the preclinical $\mathrm{AD}$ population due to findings of dose-related cognitive worsening and neuropsychiatric adverse events [31], though it has been hypothesized that a viable low dose BACE inhibition regimen could be identified in the future [32]. A number of other trials, such as the A4 study [33] or the AHEAD 3-45 Study (NCT04468659) are attempting to target the amyloid pathway with other mechanisms of action in preclinical AD.

In this study, administration of LY3202626 $3 \mathrm{mg}$ or $12 \mathrm{mg}$ once daily for 52 weeks to patients with mild AD dementia and evidence of amyloid pathology was generally well tolerated. Despite substantial reductions in the plasma levels of circulating $A \beta$ following the last treatment visit, no significant difference in clinical efficacy for cognition and function between LY3202626 and placebo were observed at either dose, which were seen in other Phase III studies testing BACE inhibitors [28-30, 34]. Moreover, no significant changes in amyloid deposition (as measured by florbetapir SUVr) or in cerebral tau neurofibrillary tangle load (as measured by flortaucipir SUVr) were observed between either treatment arm and placebo. Other markers for neurodegeneration showed mixed results, with no significant change in NfL between LY3202626 and placebo, but increased hippocampal volume loss for LY3202626 doses compared to placebo, findings which have also been observed in clinical trials with other BACE inhibitors $[28,30,34]$. In the vMRI analysis, a num- 
ber of brain regions demonstrated statistically lower volumes in LY3202626-treated patients compared to placebo-treated patients for the respective regions of interest including the hippocampus. Most concerning would be the interpretation that volumetric changes on MRI reflected actual brain atrophy. However, MRI is a noninvasive imaging modality and, while volume analysis does include neuronal parenchyma, it also includes non-neuronal constituents (i.e., nonneuronal cells) and volume components (i.e., fluids), thus making these volume changes difficult to interpret. In this study, changes in cognition were not different between LY3202626-treated patients and those administered placebo and, therefore, it appears that MRI volume reductions were not correlated with cognitive worsening.

NfL is a biomarker for neurodegeneration and, although it was numerically higher in LY3202626 groups compared to placebo, the difference was not statistically significant. The post-hoc assessment of florbetapir PET cerebral perfusion showed a statistically significant reduction in perfusion for the $12 \mathrm{mg}$ dose compared to placebo in the extrapolated annualized analysis, but no statistical significance for either dose in the LS mean change analysis for completers.

This study was limited by sample size due to early termination. In addition, without serial longitudinal follow-up MRIs or NfL measurements, we cannot definitively resolve a safety concern regarding volume changes. However, a recent study (including longitudinal data) has shown hippocampal volume reduction in umibecestat treated patients [35]. This study tested doses that resulted in mean CSF A $\beta$ inhibition of $70-87 \%$, similar to the LY3202626 doses tested in our study. The longitudinal analysis showed no progression of hippocampal volume loss between Week 26 and Week 52 scans. Furthermore, hippocampal volume reductions were not correlated with cognitive worsening, and volume reductions reversed in two months following discontinuation of umibecestat. Although this volume correction is perhaps reassuring, the mechanisms driving this reversal are not clear. Investigators theorized that contributors to the volume changes could include amyloid removal or fluid shifts. More careful monitoring is warranted in future BACE inhibitor studies.

Adverse events were more common following treatment with LY3202626 than with placebo, but no notable differences were observed between the $3 \mathrm{mg}$ and $12 \mathrm{mg}$ arms. Specifically, there were no significant differences between LY3202626 and placebo for weight loss or hair hypopigmentation as seen with other BACE inhibitors [28, 34]. With regard to non-clinical retinal concerns, there were no statistical differences for TEAEs of eye disorders or for retinal evaluations using fundoscopic and OCT assessments. A significant increase in AEs related to the psychiatric disorders system organ class were reported in both the $3 \mathrm{mg}$ and $12 \mathrm{mg}$ arms compared to placebo. Similar increases have been reported previously in trials of BACE inhibitors, such as verubecestat [28]. Furthermore, a recent study of atabecestat noted a greater number of AEs related to cognition, depression, sleep, dreams, and anxiety for patients receiving the BACE inhibitor compared to placebo [29]. Despite the fact that treatment with these compounds resulted in a greater magnitude and severity of psychiatric events (including suicidal ideation) and showed a clearer dose response relationship, these findings suggest that psychiatric reactions are adverse drug reactions associated with the BACE inhibitors class of molecules when administered at high levels of target engagement, as has been the case in several BACE inhibitors to date [28-30, 36].

The PK of LY3202626 were consistent with those described in healthy subjects, and a PK model derived from the observable plasma concentrations adequately described the overall shape of the plasma concentration-time profile and the overall dispersion of the data. High inter-subject and inter-visit variability in PK parameters were observed; however, a similar level of variability was observed in previous studies of healthy subjects, and does not seem to be unique to patients with AD. The range of LY3202626 inhibition was focused on a high degree of BACE inhibition, which was achieved using relatively low doses. The lower spectrum of BACE inhibition, such as in the range of amyloidogenic peptide reduction, $30-40 \%$, similar to the Icelandic mutation [37], was not explored. While a lower degree of BACE inhibition might result in an improved safety profile, the benefit-safety profile of lower doses would have to be confirmed in a prospective study. For clinical trials that observed cognitive worsening, speculated mechanisms have focused on axonal organization defects caused by BACE1 over-inhibition and on the consequences of BACE inhibition in non-clinical studies, indicating negative effects on synaptic function and loss of dendritic spines in mice treated with BACE inhibitor MK-8931 [38, 39]. This biological effect on synapses and dendrites is reversible after cessation of BACE1 inhibitor treatment [38] and, while it has not been confirmed clinically, the effect appears to be dose-dependent in non-clinical stud- 
ies, with lower doses of BACE inhibition having no effect on dendritic structure or spine plasticity [40]. Concordantly, recent studies have suggested that the negative effect of BACE inhibitors on cognition might be independent of the presence of brain amyloid and appears reversible after compound washout [41]. Some authors have suggested that lower BACE inhibition may have potential in future trials $[39,42$, 43].

The dual-phase florbetapir PET may hold promise as a dual-biomarker imaging approach in the measurement of amyloid pathology ("late phases" started 50 minutes post-injection and regional cerebral perfusion; "early phases" started at the time of tracer administration). This approach could reduce patient radiation exposure and imaging sessions. To our knowledge, NAVIGATE-AD is the first multi-center interventional trial in patients with $\mathrm{AD}$ where dualphase florbetapir acquisition was implemented. Further, longitudinal characteristics of perfusion imaging remain largely unknown. Our study demonstrated a significant (LS mean change of -0.03 ) decrease of perfusion for placebo participants. Among cortical Automated Anatomical Labeling atlas regions of interest, the largest relative decrease in perfusion was observed in temporal, lateral parietal, and cingulate regions. No significant association between baseline perfusion SUVr and amyloid burden was observed, suggesting an independence of these two measurements obtained using a dual-phase florbetapir scan. At the same time, a significant $(p<0.001)$ negative association between perfusion and composite neocortical tau SUVr was found. Significant associations between perfusion SUVr and ADAS- $\operatorname{Cog}_{13}$ and iADL were also observed at baseline. These analyses suggest the potential utility of regional perfusion estimates derived from early-phase florbetapir scans as a tractable alternative to ${ }^{18} \mathrm{~F}$-fluorodeoxyglucose measurements in AD trials [44]. Further exploration and validation would be required in clinical studies with more definitive positive or negative clinical outcomes to strengthen the method's utility.

In conclusion, as a BACE1 inhibitor targeting 70-90\% inhibition, LY3202626 was generally welltolerated. A significant increase in AEs related to psychiatric disorders was observed following treatment, consistent with findings in studies with other BACE inhibitors. Despite high target engagement, no clinically significant change in the primary endpoint of tau burden or in the rate of functional or cognitive decline was observed following 52 weeks of dosing (or with annualized change analysis). An efficacy interim analysis led to the early termination of the study.

\section{ACKNOWLEDGMENTS}

This study was funded by Eli Lilly and Company. The authors would like to thank Michael Irizarry, MD, MPH, and Jennifer A. Zimmer, MD, for their contributions to study design; Arnaud Charil, $\mathrm{PhD}$ for his assistance with imaging analysis; and Peng Liu, $\mathrm{PhD}$ for his assistance with statistical methodology.

The authors would also like to acknowledge the patients, investigators, and clinical staff involved in the study, as well as Kevin Christina for providing medical writing services on behalf of Covance, Inc.

\section{CONFLICT OF INTEREST}

Albert Lo, Cynthia Duggan Evans, Michele Mancini, Sergey Shcherbinin, Hong Wang, Ming Lu, Fanni Natanegara, and Brian Willis are employees of Eli Lilly and Company, Inc., and may own stock in this company.

\section{SUPPLEMENTARY MATERIAL}

The supplementary material is available in the electronic version of this article: https://dx.doi.org/ 10.3233/ADR-210296.

\section{REFERENCES}

[1] Takizawa C, Thompson PL, van Walsem A, Faure C, Maier WC (2015) Epidemiological and economic burden of Alzheimer's disease: A systematic literature review of data across Europe and the United States of America. $J$ Alzheimers Dis 43, 1271-1284.

[2] Querfurth HW, LaFerla FM (2010) Alzheimer's disease. $N$ Engl J Med 362, 329-344.

[3] Shankar GM, Li S, Mehta TH, Garcia-Munoz A, Shepardson NE, Smith I, Brett FM, Farrell MA, Rowan MJ, Lemere CA, Regan CM, Walsh DM, Sabatini BL, Selkoe DJ (2008) Amyloid-beta protein dimers isolated directly from Alzheimer's brains impair synaptic plasticity and memory. Nat Med 14, 837-842.

[4] Turner PR, O'Connor K, Tate WP, Abraham WC (2003) Roles of amyloid precursor protein and its fragments in regulating neural activity, plasticity and memory. Prog Neurobiol 70, 1-32.

[5] Brier MR, Gordon B, Friedrichsen K, McCarthy J, Stern A, Christensen J, Owen C, Aldea P, Su Y, Hassenstab J, Cairns NJ, Holtzman DM, Fagan AM, Morris JC, Benzinger TL, Ances BM (2016) Tau and Abeta imaging, CSF measures, and cognition in Alzheimer's disease. Sci Transl Med 8, 338ra366. 
[6] Xia CF, Arteaga J, Chen G, Gangadharmath U, Gomez LF, Kasi D, Lam C, Liang Q, Liu C, Mocharla VP, Mu F, Sinha A, Su H, Szardenings AK, Walsh JC, Wang E, Yu C, Zhang W, Zhao T, Kolb HC (2013) [(18)F]T807, a novel tau positron emission tomography imaging agent for Alzheimer's disease. Alzheimers Dement 9, 666-676.

[7] Chien DT, Szardenings AK, Bahri S, Walsh JC, Mu F, Xia C, Shankle WR, Lerner AJ, Su MY, Elizarov A, Kolb HC (2014) Early clinical PET imaging results with the novel PHF-tau radioligand [F18]-T808. J Alzheimers Dis 38, 171184.

[8] Fleisher AS, Pontecorvo MJ, Devous MD, Sr., Lu M, Arora AK, Truocchio SP, Aldea P, Flitter M, Locascio T, Devine M, Siderowf A, Beach TG, Montine TJ, Serrano GE, Curtis C, Perrin A, Salloway S, Daniel M, Wellman C, Joshi $\mathrm{AD}$, Irwin DJ, Lowe VJ, Seeley WW, Ikonomovic MD, Masdeu JC, Kennedy I, Harris T, Navitsky M, Southekal S, Mintun MA, A16 Study Investigators (2020) Positron emission tomography imaging with [18F]flortaucipir and postmortem assessment of Alzheimer disease neuropathologic changes. JAMA Neurol 77, 829-839.

[9] Pontecorvo MJ, Devous MD, Kennedy I, Navitsky M, Lu M, Galante N, Salloway S, Doraiswamy PM, Southekal $\mathrm{S}$, Arora AK, McGeehan A, Lim NC, Xiong H, Truocchio SP, Joshi AD, Shcherbinin S, Teske B, Fleisher AS, Mintun MA (2019) A multicentre longitudinal study of flortaucipir (18F) in normal ageing, mild cognitive impairment and Alzheimer's disease dementia. Brain 142, 1723-1735.

[10] Schwarz AJ, Shcherbinin S, Slieker LJ, Risacher SL, Charil A, Irizarry MC, Fleisher AS, Southekal S, Joshi AD, Devous MD, Sr., Miller BB, Saykin AJ, Alzheimer's Disease Neuroimaging Initiative (2018) Topographic staging of tau positron emission tomography images. Alzheimers Dement (Amst) 10, 221-231.

[11] Pontecorvo MJ, Devous MD, Sr., Navitsky M, Lu M, Salloway S, Schaerf FW, Jennings D, Arora AK, McGeehan A, Lim NC, Xiong H, Joshi AD, Siderowf A, Mintun MA, 18FAV-1451-A05 investigators (2017) Relationships between flortaucipir PET tau binding and amyloid burden, clinical diagnosis, age and cognition. Brain 140, 748-763.

[12] Willis BA, Lowe SL, Daugherty LL, Dean RA, English B, Ereshefsky L, Gevorkyan H, James DE, Jhee S, Lin Q, Lo A, Mergott DJ, Monk SA, Nakano M, Zimmer JA, Irizarry MC (2016) P1-044: Pharmacokinetics, pharmacodynamics, safety, and tolerability of LY3202626, a novel Bace1 inhibitor, in healthy subjects and patients with Alzheimer's disease. Alzheimers Dement 12 (7 Suppl), P418.

[13] Hyman BT, Phelps CH, Beach TG, Bigio EH, Cairns NJ, Carrillo MC, Dickson DW, Duyckaerts C, Frosch MP, Masliah E, Mirra SS, Nelson PT, Schneider JA, Thal DR, Thies B, Trojanowski JQ, Vinters HV, Montine TJ (2012) National Institute on Aging-Alzheimer's Association guidelines for the neuropathologic assessment of Alzheimer's disease. Alzheimers Dement 8, 1-13.

[14] Clark CM, Pontecorvo MJ, Beach TG, Bedell BJ, Coleman RE, Doraiswamy PM, Fleisher AS, Reiman EM, Sabbagh MN, Sadowsky CH, Schneider JA, Arora A, Carpenter AP, Flitter ML, Joshi AD, Krautkramer MJ, Lu M, Mintun MA, Skovronsky DM, AV-45-A16 Study Group (2012) Cerebral PET with florbetapir compared with neuropathology at autopsy for detection of neuritic amyloid-beta plaques: A prospective cohort study. Lancet Neurol 11, 669-678.

[15] Mohs RC, Knopman D, Petersen RC, Ferris SH, Ernesto C, Grundman M, Sano M, Bieliauskas L, Geldmacher D, Clark
C, Thal LJ (1997) Development of cognitive instruments for use in clinical trials of antidementia drugs: Additions to the Alzheimer's Disease Assessment Scale that broaden its scope. The Alzheimer's Disease Cooperative Study. Alzheimer Dis Assoc Disord 11(Suppl 2), S13-21.

[16] Galasko D, Bennett D, Sano M, Ernesto C, Thomas R, Grundman M, Ferris S (1997) An inventory to assess activities of daily living for clinical trials in Alzheimer's disease. The Alzheimer's Disease Cooperative Study. Alzheimer Dis Assoc Disord 11 Suppl 2, S33-39.

[17] Galasko D, Kershaw PR, Schneider L, Zhu Y, Tariot PN (2004) Galantamine maintains ability to perform activities of daily living in patients with Alzheimer's disease. $J \mathrm{Am}$ Geriatr Soc 52, 1070-1076.

[18] Wessels AM, Siemers ER, Yu P, Andersen SW, Holdridge KC, Sims JR, Sundell K, Stern Y, Rentz DM, Dubois B, Jones RW, Cummings J, Aisen PS (2015) A combined measure of cognition and function for clinical trials: The Integrated Alzheimer's Disease Rating Scale (iADRS). $J$ Prev Alzheimers Dis 2, 227-241.

[19] Posner K, Oquendo MA, Gould M, Stanley B, Davies M (2007) Columbia Classification Algorithm of Suicide Assessment (C-CASA): Classification of suicidal events in the FDA's pediatric suicidal risk analysis of antidepressants. Am J Psychiatry 164, 1035-1043.

[20] Nasreddine ZS, Phillips NA, Bedirian V, Charbonneau $\mathrm{S}$, Whitehead V, Collin I, Cummings JL, Chertkow H (2005) The Montreal Cognitive Assessment, MoCA: A brief screening tool for mild cognitive impairment. J Am Geriatr Soc 53, 695-699.

[21] Folstein MF, Folstein SE, McHugh PR (1975) “Mini-mental state" A practical method for grading the cognitive state of patients for the clinician. J Psychiatr Res 12, 189-198.

[22] Tabert MH, Albert SM, Borukhova-Milov L, Camacho Y, Pelton G, Liu X, Stern Y, Devanand DP (2002) Functional deficits in patients with mild cognitive impairment: Prediction of AD. Neurology 58, 758-764.

[23] Teng E, Becker BW, Woo E, Knopman DS, Cummings JL, Lu PH (2010) Utility of the functional activities questionnaire for distinguishing mild cognitive impairment from very mild Alzheimer disease. Alzheimer Dis Assoc Disord 24, 348-353.

[24] Farias ST, Mungas D, Reed BR, Cahn-Weiner D, Jagust W, Baynes K, Decarli C (2008) The measurement of everyday cognition (ECog): Scale development and psychometric properties. Neuropsychology 22, 531-544.

[25] Cummings JL, Mega M, Gray K, Rosenberg-Thompson S, Carusi DA, Gornbein J (1994) The Neuropsychiatric Inventory: Comprehensive assessment of psychopathology in dementia. Neurology 44, 2308-2314.

[26] Trigg R, Skevington SM, Jones RW (2007) How can we best assess the quality of life of people with dementia? the Bath Assessment of Subjective Quality of Life in Dementia (BASQID). Gerontologist 47, 789-797.

[27] Hsiao IT, Huang CC, Hsieh CJ, Hsu WC, Wey SP, Yen TC, Kung MP, Lin KJ (2012) Correlation of early-phase 18Fflorbetapir (AV-45/Amyvid) PET images to FDG images: Preliminary studies. Eur J Nucl Med Mol Imaging 39, 613620.

[28] Egan MF, Kost J, Voss T, Mukai Y, Aisen PS, Cummings JL, Tariot PN, Vellas B, van Dyck CH, Boada M, Zhang Y, Li W, Furtek C, Mahoney E, Harper Mozley L, Mo Y, Sur C, Michelson D (2019) Randomized trial of verubecestat for prodromal Alzheimer's disease. N Engl J Med 380, 14081420. 
[29] Henley D, Raghavan N, Sperling R, Aisen P, Raman R, Romano G (2019) Preliminary results of a trial of atabecestat in preclinical Alzheimer's disease. N Engl J Med 380, 14831485.

[30] Egan MF, Kost J, Tariot PN, Aisen PS, Cummings JL, Vellas B, Sur C, Mukai Y, Voss T, Furtek C, Mahoney E, Harper Mozley L, Vandenberghe R, Mo Y, Michelson D (2018) Randomized trial of verubecestat for mild-to-moderate Alzheimer's disease. N Engl J Med 378, 1691-1703.

[31] Sperling R, Henley D, Aisen PS, Raman R, Donohue MC, Ernstrom K, Rafii MS, Streffer J, Shi Y, Karcher K, Raghavan N, Tymofyeyev Y, Bogert J, Brashear HR, Novak G, Thipphawong J, Saad ZS, Kolb H, Rofael H, Sanga P, Romano G (2021) Findings of efficacy, safety, and biomarker outcomes of atabecestat in preclinical Alzheimer disease: A truncated randomized phase $2 \mathrm{~b} / 3$ clinical trial. JAMA Neurol 78, 293-301.

[32] Aisen PS, Cummings J, Doody R, Kramer L, Salloway S, Selkoe DJ, Sims J, Sperling RA, Vellas B (2020) The future of anti-amyloid trials. J Prev Alzheimers Dis 7, 146-151.

[33] Sperling RA, Rentz DM, Johnson KA, Karlawish J, Donohue M, Salmon DP, Aisen P (2014) The A4 study: Stopping AD before symptoms begin? Sci Transl Med 6, $228 \mathrm{fs} 213$.

[34] Wessels AM, Tariot PN, Zimmer JA, Selzler KJ, Bragg SM, Andersen SW, Landry J, Krull JH, Downing AM, Willis BA, Shcherbinin S, Mullen J, Barker P, Schumi J, Shering C, Matthews BR, Stern RA, Vellas B, Cohen S, MacSweeney E, Boada M, Sims JR (2020) Efficacy and safety of lanabecestat for treatment of early and mild Alzheimer disease: The AMARANTH and DAYBREAK-ALZ randomized clinical trials. JAMA Neurol 77, 199-209.

[35] Reiman EM, Tariot PN, Borowsky B, Liu F, Riviere M-E, Rouzade-Dominguez M-L, Cazorla P, Quinn M, Ricart J, Langbaum JB, Viglietta V, Sui Y, Caputo A, Graf A, Seneca N, Neumann U, Eichenlaub U, Chien Y, Arkuszewski M, Piccard H, Quarg P (2020) The API Generation program: Umibecestat treatment and discontinuation effects on hippocampal and whole brain volumes in the overall population and amyloid-negative APOE4 homozygotes. Alzheimers Dement 16(Suppl 9), e041142.

[36] Egan MF, Mukai Y, Voss T, Kost J, Stone J, Furtek C, Mahoney E, Cummings JL, Tariot PN, Aisen PS, Vellas B, Lines C, Michelson D (2019) Further analyses of the safety of verubecestat in the phase $3 \mathrm{EPOCH}$ trial of mildto-moderate Alzheimer's disease. Alzheimers Res Ther 11, 68.

[37] Jonsson T, Atwal JK, Steinberg S, Snaedal J, Jonsson PV, Bjornsson S, Stefansson H, Sulem P, Gudbjartsson D, Maloney J, Hoyte K, Gustafson A, Liu Y, Lu Y, Bhangale T, Graham RR, Huttenlocher J, Bjornsdottir G, Andreassen OA, Jonsson EG, Palotie A, Behrens TW, Magnusson OT, Kong A, Thorsteinsdottir U, Watts RJ, Stefansson K (2012) A mutation in APP protects against Alzheimer's disease and age-related cognitive decline. Nature $\mathbf{4 8 8}, 96-99$.

[38] Blume T, Filser S, Jaworska A, Blain JF, Koenig G, Moschke K, Lichtenthaler SF, Herms J (2018) BACE1 inhibitor MK8931 alters formation but not stability of dendritic spines. Front Aging Neurosci 10, 229.

[39] Vassar R (2019) Editorial: Implications for BACE1 inhibitor clinical trials: Adult conditional BACE1 knockout mice exhibit axonal organization defects in the hippocampus. $J$ Prev Alzheimers Dis 6, 78-84.

[40] Filser S, Ovsepian SV, Masana M, Blazquez-Llorca L, Brandt Elvang A, Volbracht C, Muller MB, Jung CK, Herms J (2015) Pharmacological inhibition of BACE1 impairs synaptic plasticity and cognitive functions. Biol Psychiatry 77, 729-739.

[41] Graf A, Riviere M-E, Liu F, Rouzade-Dominguez M-L, Cazorla P, Quinn M, Arkuszewski M, Ricart J, Langbaum JB, Piccard H, Sui Y, Quarg P, Caputo A, Reiman EM, Tariot PN (2020) Umibecestat in the API Generation program: Worsening in RBANS and/or CDR on treatment reverses after wash-out. Alzheimers Dement 16(Suppl 9), e041140.

[42] Satir TM, Agholme L, Karlsson A, Karlsson M, Karila P, Illes S, Bergstrom P, Zetterberg H (2020) Partial reduction of amyloid beta production by beta-secretase inhibitors does not decrease synaptic transmission. Alzheimers Res Ther 12, 63.

[43] Zhu K, Peters F, Filser S, Herms J (2018) Consequences of pharmacological BACE inhibition on synaptic structure and function. Biol Psychiatry 84, 478-487.

[44] Shcherbinin S, Hesterman J, Devous Sr. MD, Natanegara F, You W, Evans CD, Collins EC, Lo A, Sims JR, Mintun MA (2019) P3-026: Implementation of dual-phase Florbetapir PET in the multicenter phase 2 NAVIGATE-AD clinical trial. Alzheimers Dement 15(7 Suppl), P935. 